Modern Physics Letters B

Vol. 28, No. 29 (2014) 1430014 (16 pages)

(C) World Scientific Publishing Company

DOI: $10.1142 /$ S0217984914300142

\title{
A brief review of Badger-Bauer rule and its validation from a first-principles approach
}

\author{
Ram S. Bhatta*, Prasad P. Iyer ${ }^{\dagger}$, Ali Dhinojwala and Mesfin Tsige $^{\ddagger}$ \\ Department of Polymer Science, The University of Akron, \\ Akron, Ohio 44325, USA \\ *rsb20@zips.uakron.edu \\ ¥mtsige@uakron.edu
}

Received 31 August 2014

Accepted 22 September 2014

Published 18 November 2014

\begin{abstract}
Understanding the acid-base interactions is important in chemistry, biology and material science as it helps to rationalize materials properties such as interfacial properties, wetting, adhesion and adsorption. Quantitative relation between changes in enthalpy $(\Delta H)$ and frequency shift $(\Delta \nu)$ during the acid-base complexation is particularly important. We investigate $\Delta H$ and $\Delta \nu$ of twenty-five complexes of acids (methanol, ethanol, propanol, butanol and phenol) with bases (benzene, pyridine, DMSO, $\mathrm{Et}_{2} \mathrm{O}$ and THF) in $\mathrm{CCl}_{4}$ using intermolecular perturbation theory calculations. $\Delta H$ and $\Delta \nu$ of complexes of all alcohols with bases except benzene fall in the range from $-14 \mathrm{~kJ} \mathrm{~mol}^{-1}$ to $-30 \mathrm{~kJ} \mathrm{~mol}^{-1}$ and $215 \mathrm{~cm}^{-1}$ to $523 \mathrm{~cm}^{-1}$, respectively. Smaller values of $\Delta H$ $\left(-2 \mathrm{~kJ} \mathrm{~mol}^{-1}\right.$ to $\left.-6 \mathrm{~kJ} \mathrm{~mol}^{-1}\right)$ and $\Delta \nu\left(23 \mathrm{~cm}^{-1}\right.$ to $\left.70 \mathrm{~cm}^{-1}\right)$ are estimated for benzene. Linear correlations are found between theoretical and experimental values of $\Delta H$ as well as $\Delta \nu$. For all the studied complexes, $\Delta H$ varies linearly $\left(R^{2} \geq 0.97\right)$ with $\Delta \nu$ concurrent with the Badger-Bauer rule yielding the average slope and intercept of $0.053( \pm 0.002) \mathrm{kJ} \mathrm{mol}^{-1} \mathrm{~cm}$ and $2.15( \pm 0.56) \mathrm{kJ} \mathrm{mol}^{-1}$, respectively.
\end{abstract}

Keywords: Badger-Bauer rule; linear correlation; perturbation theory; solvation.

\section{Introduction}

The fundamental reaction of an acid and a base proposed originally by Lewis ${ }^{1}$ is the formation of an acid-base complex. The acid-base complex is formed by sharing an electron-pair between an acid and an electron-pair donating base. Such acid-base reactions to form complexes play an important role in chemistry, biology and materials science. For example, interfacial properties in polymer blends, ${ }^{2,3}$ adhesion, ${ }^{4,5}$

\footnotetext{
*, $\ddagger$ Corresponding authors.

${ }^{\dagger}$ Present address: University of California, Santa Barbara, USA.
} 


\section{R. S. Bhatta et al.}

adsorption, ${ }^{6}$ glass transition temperature,${ }^{7}$ swelling, ${ }^{8}$ and ice nucleation and cirrus cloud formation in the environment ${ }^{9}$ are affected by these acid-base complexations.

Extensive research on stability and thermodynamics of acid-base complex formation began in the 1960s. Pearson ${ }^{10}$ introduced qualitative acid-base scales based on hard and soft acids and bases (HSAB) principles to understand the stability of the acid-base complex in liquid solutions. Lee ${ }^{11}$ extended HSAB principles to solid-solid interactions including metals and semiconductors. Drago ${ }^{12,13}$ proposed a four-parameter equation to calculate the enthalpy of acid-base complex in the gas phase or in inert solvents from the susceptibilities of the acid and the base to undergo an electrostatic and a covalent interaction. Accordingly, stable acid-base complex is formed when both the acid and the base have large susceptibilities. Gutmann ${ }^{14}$ proposed a two-parameter equation to estimate enthalpy of acid-base complex, equally valid for complexes of amphoteric species, based on an acceptor number of the acid and a donor number of the base.

In addition to thermodynamic properties, the formation of hydrogen-bonded acid-base (H-bonded acid-base) complex, $\mathrm{X}-\mathrm{H} \cdots B$, also changes spectral properties, $\mathrm{X}-\mathrm{H}$ and $B$ representing acid and base, respectively. For instance, the stretching vibration of the $\mathrm{X}-\mathrm{H}$ bond shifts to lower frequency upon complex formation, and the frequency shift $(\Delta \nu)$ is related to the strength of base, possibly because of the charge transfer that changes the force constant. ${ }^{15}$ Hydrogen bonded complexes are also characterized by low-field shift in the NMR spectrum. ${ }^{16}$ Hence, a relationship between $\Delta \nu$ and thermodynamic properties is expected. Badger and Bauer ${ }^{17}$ proposed the first relation between $\Delta \nu$ and the enthalpy change $(\Delta H)$ in $\mathrm{CS}_{2}$ or $\mathrm{CCl}_{4}$ solution of H-bonded alcohol complexes. The magnitude of $\Delta \nu$ is the difference between $\mathrm{O}-\mathrm{H}$ frequency of free acid and $\mathrm{O}-\mathrm{H}$ frequency of $\mathrm{H}$-bonded acid. $\Delta H$ is the enthalpy change in acid-base complexation that corresponds to the difference between the enthalpy of acid-base complex and the sum of enthalpies of acid and base in dilute solution. The Badger-Bauer rule states that the greater the value of $\Delta H$, the larger the value of $\Delta \nu$, which allows an efficient estimation of $\Delta H$ from a simple infrared spectrum using the linear equation,

$$
-\Delta H\left(\mathrm{~kJ} \mathrm{~mol}^{-1}\right)=m \Delta \nu\left(\mathrm{cm}^{-1}\right)+c .
$$

Here, $m$ and $c$ are the slope and the intercept of $\Delta H$ versus $\Delta \nu$ plot, respectively.

Over the past 70 years, a large number of experimental studies ${ }^{13,15,18-35}$ focused on determining $\Delta H$ and $\Delta \nu$. Most of these studies were carried out to validate Badger-Bauer relation for acid-base interactions. These studies were on reference acids such as aliphatic alcohols, phenol and their substituted derivatives. In these works, the hydrogen-bond donor was constant and the universal applicability of Eq. (1) was tested for a broad range of acceptor molecules (Table 1). As can be seen in Table 1, the reported slope $(m)$ and the intercept $(c)$ range from $0.043 \mathrm{~kJ} \mathrm{~mol}^{-1}$ to $0.13 \mathrm{~kJ} \mathrm{~mol}^{-1} \mathrm{~cm}$ and $-9.11 \mathrm{~kJ} \mathrm{~mol}^{-1}$ to $15.06 \mathrm{~kJ} \mathrm{~mol}^{-1}$, respectively for different donor-acceptor systems. Hence, the Badger-Bauer relation has been in the past, and is still, a subject of debate. 
Table 1. Values of $m$ and $c$ of Eq. (1) for acid-base complexes from previous studies.

\begin{tabular}{lrlccc}
\hline \multicolumn{1}{c}{ Acid-base complex } & $n$ & \multicolumn{1}{c}{ Solvent } & $m\left(\mathrm{~kJ} \mathrm{~mol}{ }^{-1} \mathrm{~cm}\right)$ & $c\left(\mathrm{~kJ} \mathrm{~mol}{ }^{-1}\right)$ & Refs. \\
\hline Methanol-base & 41 & $\mathrm{CCl}_{4}$ & 0.0438 & 7.73 & 15 \\
Methanol-base & 23 & $\mathrm{CCl}_{4}$ & 0.0479 & 6.57 & 28 \\
Butanol-base & 16 & $\mathrm{CCl}_{4}, \mathrm{C}_{2} \mathrm{Cl}_{4}$ & 0.04435 & 6.904 & 24 \\
4-fluorophenol-fluoroalkanes & 4 & $\mathrm{CCl}_{4}$ & 0.13 & 5.4 & 30 \\
4-fluorophenol-chloroalkanes & 5 & $\mathrm{CCl}_{4}$ & 0.12 & -0.4 & 30 \\
4-fluorophenol-bromoalkanes & 4 & $\mathrm{CCl}_{4}$ & 0.1 & -0.9 & 30 \\
4-fluorophenol-iodooalkanes & 5 & $\mathrm{CCl}_{4}$ & 0.09 & -1.45 & 30 \\
Hexafluoropropanol-base & 11 & $\mathrm{CCl}_{4}$ & 0.0481 & 15.06 & 31 \\
2,2,2-trifluoroethanol-base & 11 & $\mathrm{CCl}_{4}, \mathrm{C}_{6} \mathrm{H}_{14}$ & 0.0506 & 11.29 & 33 \\
Cholesterol/alcohol-base & 17 & $\mathrm{CCl}_{4}$ & 0.055 & 7.45 & 26 \\
Phenol-base & 15 & $\mathrm{CCl}_{4}$ & 0.0669 & 2.635 & 27 \\
Phenol-base & 9 & $\mathrm{CCl}_{4}, \mathrm{C}_{6} \mathrm{H}_{14}$ & 0.046 & 11.67 & 25 \\
Substituted phenol-base & 16 & $\mathrm{CCl}_{4}$ & 0.04309 & 12.88 & 23,35 \\
3,5-dichlorophenol-ether & 8 & $\mathrm{C}_{6} \mathrm{H}_{12}$ & 0.108 & -9.11 & 18 \\
\hline
\end{tabular}

Due to the advancement of quantum chemical computations, it is now possible to compute reliable $\Delta H$ and $\Delta \nu$ values for acid-base interactions and compare them with the reported experimental data, which makes it possible to directly validate the Badger-Bauer relation. A few quantum chemical calculations of complexation energies of water-complex ${ }^{36}$ and methanol-complex ${ }^{37}$ in the gas phase have been reported, concluding that complexation energies calculated using B3LYP and MP2 methods are generally reliable. Recently, Kone et al. ${ }^{28}$ have reported quantum chemical calculations of $\Delta H$ and $\Delta \nu$ at B3LYP and MP2 levels for hydrogen-bonded complexes between methanol and twenty-three bases in the gas phase. $\Delta H$ and $\Delta \nu$ computed at the B3LYP $/ 6-31+\mathrm{G}(\mathrm{d}, \mathrm{p})$ level are found to be correlated with the values of $0.0436( \pm 0.0073)$ and $6.07( \pm 2.09)$ for $m$ and $c$ [Eq. (1)], respectively. Since experimental studies are performed in suitable solvents, in most cases in $\mathrm{CCl}_{4}$, direct comparison of calculated results in the gas phase with the experimental data is challenging. To our knowledge, quantum chemical calculations on the correlation between $\Delta H$ and $\Delta \nu$ for hydrogen-bonded complexes involving broad range of $\Delta H$ and $\Delta \nu$ in solvents are not reported yet.

The main objective of this study is to test the correlation between $\Delta H$ and $\Delta \nu$ for hydrogen-bonded complexes between alcohols and bases in $\mathrm{CCl}_{4}$ solvent employing quantum chemical calculations. For this comparison, five alcohols (methanol, ethanol, propanol, $n$-butanol and phenol) and five bases (benzene, diethyl ether, dimethyl sulfoxide, tetrahydrofuran and pyridine) are considered. The present study serves as an interesting test of the relationship for the following reasons:

(i) Enthalpy and frequency shift are calculated in $\mathrm{CCl}_{4}$ solvated medium.

(ii) Five hydrogen-bond ( $\mathrm{HB})$ donors including aliphatic and aromatic alcohols are considered. 


\section{R. S. Bhatta et al.}

(iii) Five HB acceptors with different atomic sites such as C, O, N are considered, ranging from weak donor, benzene, to strong donor, pyridine.

(iv) Twenty-five HB complexes are considered that have $\Delta H$ and $\Delta \nu$ in a broad range; $\Delta H$ from $\sim 2 \mathrm{~kJ} \mathrm{~mol}^{-1}$ to $\sim 30 \mathrm{~kJ} \mathrm{~mol}{ }^{-1}$ and $\Delta \nu$ from $\sim 20 \mathrm{~cm}^{-1}$ to $\sim 500 \mathrm{~cm}^{-1}$.

\section{Computational Methods}

The second-order Moller-Plesset perturbation (MP2) theory combined with the basis set $6-31+\mathrm{G}(\mathrm{d}, \mathrm{p})$ was applied to perform calculations. ${ }^{38}$ The geometries of isolated acid and base molecules were fully optimized initially in the gas phase. Starting from these optimized geometries, minimum energy geometries of acid-base complexes were then fully optimized as done previously for methanol complexes. ${ }^{28}$ Starting from each of these fully-optimized geometries, vibrational frequencies of all thirty-five minimum-energy geometries were calculated in the harmonic approximation at the same level and are scaled by 0.939 . Minimum energy of each structure was confirmed from all-positive normal-mode frequencies because, each negative frequency, if produced, represents a transition state on a potential energy surface (PES). All theoretical calculations were performed using the Gaussian 09 (G09) package ${ }^{39}$ in vacuum as well as in $\mathrm{CCl}_{4}$ solvated medium. Solvation effect of $\mathrm{CCl}_{4}$ was modeled using the polarizable continuum method (PCM) ${ }^{40}$ The PCM method has been validated as a reliable method to describe spectroscopic and thermodynamic properties in solution. ${ }^{41,42}$

For the hydrogen-bonded acid-base complexation,

$$
\mathrm{XOH}+: B \Leftrightarrow \mathrm{XOH} \cdots B,
$$

the enthalpy of complex formation, $\Delta H$, of a hydrogen-bonded complex is the enthalpy change of the reaction [Eq. (2)] at $298 \mathrm{~K}$ and 1 atm. It was calculated using G09 directly from appropriate sums and differences of enthalpies of reactants and products as

$$
\Delta H=H_{\text {complex }}-\left(H_{\text {acid }}+H_{\text {base }}\right) .
$$

Here, $\Delta H$ is the result of contribution of different terms as ${ }^{28}$

$$
\Delta H=\Delta E_{\mathrm{el}}+\Delta \mathrm{ZPE}+\Delta E_{\mathrm{rot}}+\Delta E_{\mathrm{trans}}+\Delta E_{\mathrm{vib}}+\Delta n R T+\mathrm{BSSE} .
$$

In Eq. (4), the first term is the change in electronic interaction energy. The second term is the change in zero point vibrational energy. The ZPE is the difference in energy of equilibrium geometry (lowest point on PES) and the energy of vibrationless energy level, $v=0 . \Delta E_{\mathrm{rot}}, \Delta E_{\text {trans }}$ and $\Delta E_{\mathrm{vib}}$ are changes in rotational, translational and vibrational energies in going from $0 \mathrm{~K}$ to $298 \mathrm{~K}$, respectively. The last two terms account for the change in moles and basis set superposition errors (BSSE), respectively.

The BSSE was calculated using the counterpoise method ${ }^{43}$ implemented in G09 for gas phase complexes. However, it is not possible to perform both counterpoise 
and PCM methods directly in G09. Alternatively, the usual approach ${ }^{44,45}$ to account for both BSSE and solvation effects is to calculate BSSE in a vacuum and then add solvation correction to the total interaction energies. The BSSE corrected enthalpy, $\Delta H_{\text {solv }}^{\text {corr }}$, in solvent is given by

$$
\Delta H_{\mathrm{solv}}^{\mathrm{BSSE}}=\Delta H_{\mathrm{vac}}^{\mathrm{BSSE}}+\Delta H_{\mathrm{solv}}^{\mathrm{corr}} .
$$

Here, $\Delta H_{\mathrm{vac}}^{\mathrm{BSSE}}$ is the BSSE corrected enthalpy change in gas-phase and $\Delta H_{\mathrm{solv}}^{\text {corr }}$ is the solvation correction term. $\Delta H_{\text {solv }}^{\text {corr }}$ is the difference between enthalpies in solvent and in gas-phase without BSSE correction given by the following equation:

$$
\Delta H_{\mathrm{solv}}^{\mathrm{corr}}=\Delta H_{\mathrm{solv}}-\Delta H_{\mathrm{vac}}
$$

For simplicity, the superscript "BSSE" is dropped and enthalpy changes represented throughout following sections represent the BSSE corrected ones unless otherwise indicated. The shift in the $\mathrm{O}-\mathrm{H}$ frequency upon the hydrogen-bonded complex formation was calculated as a difference of $\mathrm{O}-\mathrm{H}$ frequency of free acid and $\mathrm{O}-\mathrm{H}$ frequency of $\mathrm{H}$-bonded acid in $\mathrm{CCl}_{4}$.

$$
\Delta \nu_{\mathrm{OH}}=\Delta \nu_{\mathrm{OH}}^{\text {free acid }}-\Delta \nu_{\mathrm{OH}}^{\text {hydrogen bonded acid }} .
$$

\section{Results and Discussion}

\subsection{Benchmark calculations}

A frequently encountered challenge in the high-level first-principles calculations using large basis set is that the disk space and memory increase tremendously. For example, the size of the basis functions at the MP2/6-31+G(d,p), MP2/ccpVTZ and MP2/aug-cc-pVTZ levels for methanol-MDSO complex are 184, 324 and 510 , respectively. Hence, moving from $6-31+\mathrm{G}(\mathrm{d}, \mathrm{p})$ to cc-pVTZ amount of resource needed for computations increases by a factor of $\sim 16$. Similarly, augmentation of cc-pVTZ increases the resource requirement by another factor of 10 . In the context of the present work, test calculations were performed on methanol complexes using different basis sets to find the reliable basis set with less computational expenses.

Figure 1 compares computed enthalpy changes in $\mathrm{CCl}_{4}$ at $6-31+\mathrm{G}(\mathrm{d}, \mathrm{p})$, ccpVTZ and aug-cc-pVTZ basis sets with the experimental values. Computed results are quantitatively different depending on the level of calculations. Specifically, MP2/6-31+G(d,p) results tend to slightly underestimate whereas MP2/cc-pVTZ and MP2/aug-cc-pVTZ results tend to slightly overestimate enthalpy changes compared to the experimental values. This shows that the MP2/6-31+G(d,p) results are close to the experimental results, captures essential physics and can be performed at less expensive computational. In the present work, the reported calculations are at MP2/6-31+G(d,p) unless otherwise indicated. 


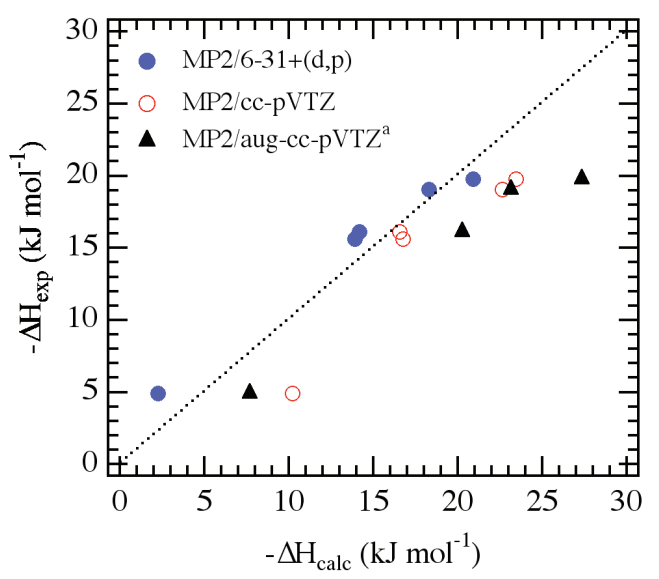

Fig. 1. (Color online) Correlation of experimental and computed enthalpy changes of methanol complexes with benzene, DMSO, THF, Et ${ }_{2} \mathrm{O}$ and pyridine molecules in $\mathrm{CCl}_{4}$ at different compu-

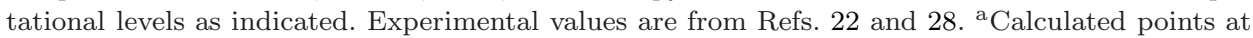
MP2/aug-cc-pVTZ in vacuum was taken from Ref. 28 and was corrected for solvation computing at MP2/cc-pVTZ.

\subsection{Geometries of acid-base complexes and hydrogen bonding}

The minimum energy structures of 25 acid-base complexes are depicted in Fig. 2. Hydrogen bonding on each of these complexes is formed between a lone pair of electrons in the highest occupied molecular orbital (HOMO) of a base and a lowest unoccupied molecular orbital (LUMO) of an acid. In other words, a base acts as an electron pair (HOMO electrons) donor and an acid acts as an electron pair acceptor (shared to LUMO) to form the hydrogen bond of an acid-base complex. The positive (blue) and the negative (red) phases of HOMO orbitals are also shown (Fig. 2) for each complex. The orientation of these orbitals provides valuable information on the directionality of the hydrogen bond. In each minimum-energy acid-base complex, the HOMO orbital of a base is oriented toward the hydrogen atom of $\mathrm{OH}$ group of an acid. This preferred orientation of HOMO orbital forms a stable acid-base complex.

In the minimum energy benzene complexes, as seen in Fig. 1, the hydroxyl group of each aliphatic alcohol faces to the center of the $\mathrm{C}-\mathrm{C}$ bond rather than to the center of the aromatic ring because of the fact that HOMO orbital is localized on $\mathrm{C}-\mathrm{C}$ bond length. In the case of phenol-benzene complex, both the hydroxyl group and the $\mathrm{C}-\mathrm{H}$ bond of the phenol are bound on a carbon-carbon bond of the benzene ring. This makes the hydrogen-bonded complex for benzene with phenol unique geometry compared to complexes of benzene with aliphatic alcohols. The structure of both of these complexes match the structure reported for methanol-benzene ${ }^{28}$ and phenol-benzene complexes. ${ }^{46}$

The key structural parameter for acid-base complexes (Fig. 2) is hydrogen bond (HB) length (Table 2). Figure 3 shows the variation of HB length for different 


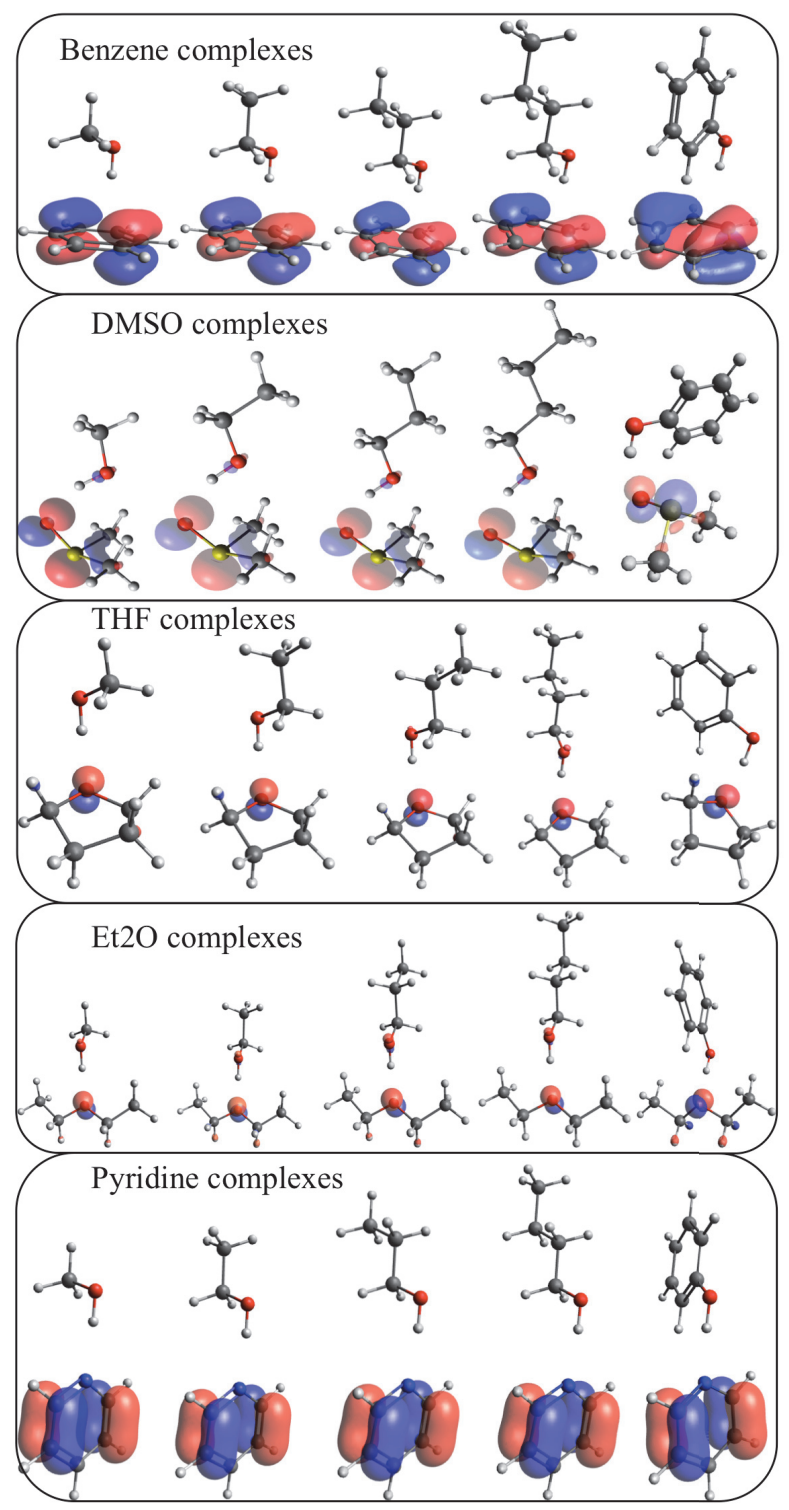

Fig. 2. (Color online) Molecular structures of hydrogen-bonded acid-base complexes. Hydrogen bond acceptors are oriented towards the frontier molecular orbital of hydrogen bond donors. For each orbital, red and blue colors represent the negative and positive phases, respectively.

complexes in $\mathrm{CCl}_{4}$ solvent. For a given base, there is a slight variation of $\mathrm{HB}$ lengths among aliphatic alcohols (Fig. 3). Average HB lengths of aliphatic alcohols with benzene, pyridine, $\mathrm{Et}_{2} \mathrm{O}$, THF and DMSO are $2.5129 \AA, 1.8264 \AA, 1.8263 \AA$, $1.8262 \AA$ and $1.8068 \AA$, respectively. As expected, HB lengths of phenol-base complexes are shorter than corresponding aliphatic acid counterparts. HB distances 


\section{R. S. Bhatta et al.}

Table 2. Values of enthalpy change, frequency shift, change in $\mathrm{OH}$ bond and hydrogen bond length for different HB donor-accepter complexes.

\begin{tabular}{|c|c|c|c|c|c|c|c|}
\hline $\begin{array}{c}\text { HB } \\
\text { donor }\end{array}$ & $\begin{array}{c}\mathrm{HB} \\
\text { acceptor }\end{array}$ & $\begin{array}{c}\Delta H \\
(\mathrm{~kJ} \mathrm{~mol}-1)\end{array}$ & $\begin{array}{c}\Delta \nu \\
\left(\mathrm{cm}^{-1}\right)\end{array}$ & $\begin{array}{c}\Delta r_{\mathrm{OH}} \\
\left(10^{-2} \AA\right)\end{array}$ & $\begin{array}{l}\mathrm{HB} \\
(\AA)\end{array}$ & $\begin{array}{c}\Delta H^{\mathrm{a}} \\
\left(\mathrm{kJ} \mathrm{mol}^{-1}\right)\end{array}$ & $\begin{array}{c}\Delta \nu^{\mathrm{b}} \\
\left(\mathrm{cm}^{-1}\right)\end{array}$ \\
\hline Methanol & Benzene & 2.25 & 24.2 & 0.186 & 2.5244 & 4.88 & 29 \\
\hline Methanol & DMSO & 20.92 & 314.3 & 1.597 & 1.8067 & 19.77 & 213 \\
\hline Methanol & $\mathrm{Et}_{2} \mathrm{O}$ & 13.93 & 215.7 & 1.086 & 1.8313 & 15.60 & 170 \\
\hline Methanol & Pyridine & 18.3 & 318.2 & 1.585 & 1.8848 & 19.05 & 286 \\
\hline Methanol & $\mathrm{THF}$ & 14.17 & 219.6 & 1.143 & 1.8262 & 16.11 & 155 \\
\hline Ethanol & Benzene & 5.26 & 23.4 & 0.187 & 2.5213 & & \\
\hline Ethanol & DMSO & 20.51 & 311.6 & 1.591 & 1.809 & & \\
\hline Ethanol & $\mathrm{Et}_{2} \mathrm{O}$ & 13.85 & 215.7 & 1.088 & 1.8287 & & \\
\hline Ethanol & Pyridine & 17.68 & 316.7 & 1.585 & 1.8847 & & \\
\hline Ethanol & THF & 14.04 & 220.1 & 1.143 & 1.8263 & & \\
\hline$n$-Propanol & Benzene & 3.06 & 23.8 & 0.181 & 2.5062 & & \\
\hline$n$-Propanol & DMSO & 20.64 & 315.1 & 1.608 & 1.8059 & & \\
\hline$n$-Propanol & $\mathrm{Et}_{2} \mathrm{O}$ & 14.11 & 220.2 & 1.105 & 1.8227 & & \\
\hline$n$-Propanol & Pyridine & 17.85 & 319.4 & 1.599 & 1.8815 & & \\
\hline$n$-Propanol & $\mathrm{THF}$ & 14.53 & 220 & 1.145 & 1.8264 & & \\
\hline$n$-Butanol & Benzene & 1.96 & 27.5 & 0.194 & 2.5 & 2.10 & 20 \\
\hline$n$-Butanol & DMSO & 19.44 & 318.4 & 1.622 & 1.8059 & 19.61 & 200 \\
\hline$n$-Butanol & $\mathrm{Et}_{2} \mathrm{O}$ & 12.96 & 222.3 & 1.109 & 1.8229 & 12.60 & 147 \\
\hline$n$-Butanol & Pyridine & 16.66 & 323.4 & 1.611 & 1.8801 & 18.91 & 264 \\
\hline$n$-Butanol & THF & 14.67 & 248.5 & 1.242 & 1.8257 & 12.95 & 153 \\
\hline Phenol & Benzene & 6.12 & 70 & 0.347 & 2.4005 & 6.53 & 46 \\
\hline Phenol & DMSO & 23.98 & 404.3 & 2.082 & 1.7433 & 27.20 & 357 \\
\hline Phenol & $\mathrm{Et}_{2} \mathrm{O}$ & 22.75 & 356.1 & 1.725 & 1.7381 & 22.80 & 275 \\
\hline Phenol & Pyridine & 28.28 & 523.6 & 2.631 & 1.7748 & 29.29 & 475 \\
\hline Phenol & THF & 22.7 & 376.4 & 1.864 & 1.7253 & 23.43 & 285 \\
\hline
\end{tabular}

a,b Experimental values in $\mathrm{CCl}_{4}$ from Refs. 20, 22, 28, 29, 32 and 34 .

of phenol complexes with benzene, pyridine, $\mathrm{Et}_{2} \mathrm{O}$, THF and DMSO decrease by $0.1124 \AA, 0.1079 \AA, 1.008 \AA, 0.0883 \AA$ and $0.0635 \AA$, respectively compared to aliphatic alcohol complexes.

The different HB length for aliphatic and phenol complexes with a given base can be understood in terms of different acidic strengths. All carbon atoms in phenol are $s p^{2}$ hybridized and actual $\mathrm{C}-\mathrm{C}$ bonds can be best considered as represented by the resonance structures. In contrast, carbon atoms in aliphatic alcohols are $s p^{3}$ hybridized and are saturated. Resonance structures of phenol stabilize oxygen anion from the $\mathrm{OH}$ group and hence the hydrogen atom in phenol is loosely bound compared to the hydrogen atom of aliphatic alcohols. Consequently, loosely-bound hydrogen atom forms stronger HB with the base. In other words, stronger HB has shorter HB length. Phenol derivatives such as 4-fluorophenol and 4-nitrophenol are even stronger acids than phenol and form stronger HB. ${ }^{47}$ 


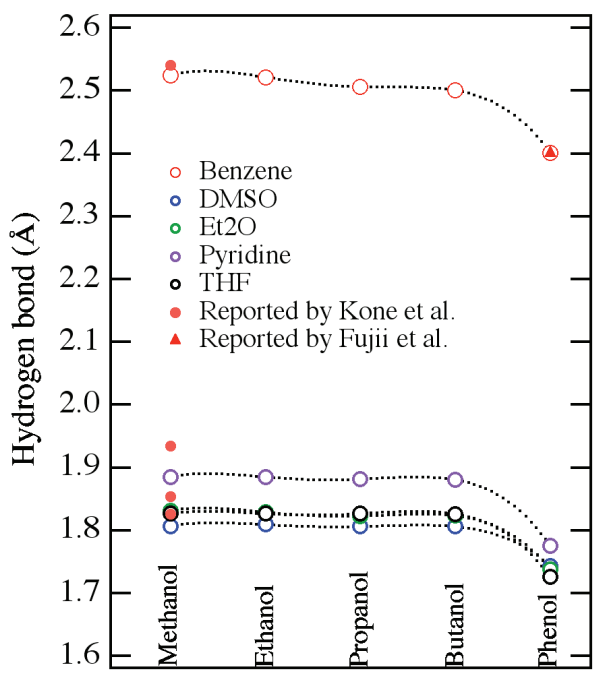

Fig. 3. (Color online) Variation of hydrogen-bond length across acid-base complexes in $\mathrm{CCl}_{4}$. Data represented by filled circle (from Ref. 28) and triangle (from Ref. 46). Symbols are for complexes in the gas phase.

Variations of HB lengths across acid-base complexes have been studied in a vacuum (filled circles and triangle in Fig. 3). ${ }^{28,46}$ Kone et al. ${ }^{28}$ have reported HB lengths of $2.540 \AA, 1.934 \AA, 1.853 \AA$ and $1.826 \AA$, respectively for methanol complexes with benzene, pyridine, THF and DMSO. Fujji et al. ${ }^{46}$ have reported HB length of $2.417 \AA$ for the phenol-benzene complex. We have also computed HB lengths of these complexes in vacuum and results agree very closely with the reported values. Comparison of $\mathrm{HB}$ lengths in vacuum and $\mathrm{CCl}_{4}$ mediums shows that the solvation affects HB lengths. For instant, the decrease in HB length going from vacuum to $\mathrm{CCl}_{4}$ solvent is $\sim 0.002 \AA$ for phenol complexes and $\sim 0.03 \AA$ for methanol complexes. These changes on HB length have strong effect on $\Delta \nu$.

\section{3. $\mathrm{O}-\mathrm{H}$ frequency shift}

Infrared spectroscopy plays an important role in understanding acid-base interactions and $\mathrm{HB}$ formations because of its sensitivity to the presence of $\mathrm{HB}$. In $\mathrm{XO}-\mathrm{H} \cdots B$ complex, $\mathrm{HB}$ is characterized by weakening (lengthening) of the $\mathrm{O}-\mathrm{H}$ bond because of the electrostatic attraction between $\mathrm{H}$ and $\mathrm{B}$. This reduces the force constant of the $\mathrm{O}-\mathrm{H}$ bond and consequently, $\mathrm{O}-\mathrm{H}$ stretching frequency is decreased. ${ }^{48}$ Hence, the basis of the spectroscopic study of $\mathrm{HB}$ is that $\mathrm{O}-\mathrm{H}$ frequency of $\mathrm{XO}-\mathrm{H} \cdots B$ complex shifts to lower frequency compared to the $\mathrm{O}-\mathrm{H}$ frequency of free acid, $\mathrm{XO}-\mathrm{H}$. This difference in $\mathrm{O}-\mathrm{H}$ frequencies, $\Delta \nu_{\mathrm{OH}}$, is expected to correlate very well with the $\mathrm{O}-\mathrm{H}$ bond-length changes $\left(\Delta r_{\mathrm{OH}}\right)$ during the $\mathrm{HB}$ bond formation. In fact, good correlations between $\Delta \nu_{\mathrm{OH}}$ and $\Delta r_{\mathrm{OH}}$ have been reported for similar systems. ${ }^{49}$ 


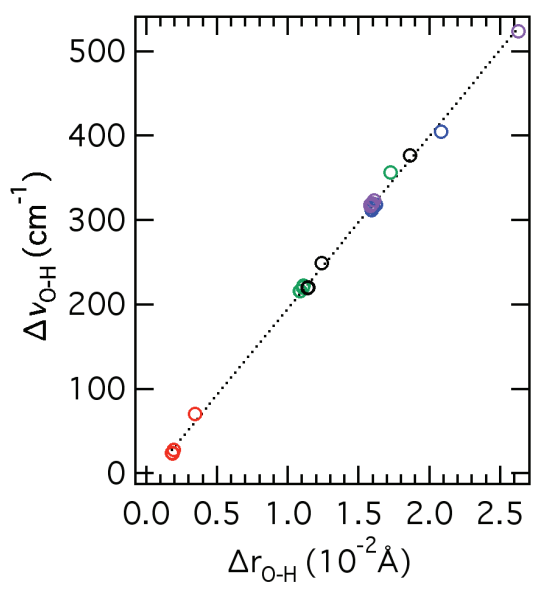

Fig. 4. (Color online) Variation of $\mathrm{O}-\mathrm{H}$ frequency shift as a function of $\mathrm{O}-\mathrm{H}$ bond elongation for twenty-five hydrogen bonded complexes. The color scheme is the same as in Fig. 3.

Figure 4 shows the correlation between $\Delta \nu_{\mathrm{OH}}$ and $\Delta r_{\mathrm{OH}}$ for twenty-five hydrogen-bonded complexes in $\mathrm{CCl}_{4}$ solvent. Among these complexes, weaker base, benzene, involves smaller $\Delta r_{\mathrm{OH}}$ values $(\sim 0.0019 \AA$ for aliphatic alcohols and $0.0035 \AA$ for phenol). Corresponding $\Delta \nu_{\mathrm{OH}}$ values for benzene complexes are $\sim 24 \mathrm{~cm}^{-1}$ for aliphatic alcohols and $70 \mathrm{~cm}^{-1}$ for phenol (Table 2). Complexes with the strong base, pyridine, have larger values of $\Delta \nu_{\mathrm{OH}}$ and $\Delta r_{\mathrm{OH}}$. For all complexes, $\Delta \nu_{\mathrm{OH}}$ and $\Delta r_{\mathrm{OH}}$ are perfectly correlated in a linear equation, $\Delta \nu_{\mathrm{OH}}\left(\mathrm{cm}^{-1}\right)=20442 \Delta r_{\mathrm{OH}}(\AA)-9.6$ with $R^{2}=0.998$. Recently, Wang et al. ${ }^{50}$ have reported similar correlation between frequency shift and bond length variation in halogen-bonded complexes.

The $\mathrm{O}-\mathrm{H}$ frequency shift in acid-base complex formation can be understood in terms of molecular orbital interactions. In $\mathrm{XO}-\mathrm{H} \cdots B$, complex molecular orbitals are formed mixing HOMO orbitals of base and the LUMO orbitals of acid. The mixing of these orbitals leads to the intersystem electron density shift from one fragment (base) to another (acid). As a result, the electron density is increased towards $\mathrm{O}-\mathrm{H}$ of acid, $\mathrm{H}$ is pulled towards $\mathrm{B}$ and $\mathrm{O}-\mathrm{H}$ bond is weakened. This shifts the $\mathrm{O}-\mathrm{H}$ frequency of complex to the lower wavelength. In addition to the effect on spectral property, hydrogen bonding is also known to affect the properties of crystalline and polymeric systems. ${ }^{51-55}$

\subsection{Enthalpy of complex formation}

Experimentally, $\Delta H$ values are often measured in suitable solvent. Hence, the direct comparison of computed $\Delta H$ values with corresponding experimental data requires the computation of $\Delta H$ also in suitable solvent, as values of $\Delta H$ are expected to be different in gas phase than in solvent. ${ }^{33}$ In the present study, we have selected $\mathrm{CCl}_{4}$ as a solvent for the computation of $\Delta H$ for acid-base complexes. Figure $5($ a) shows 

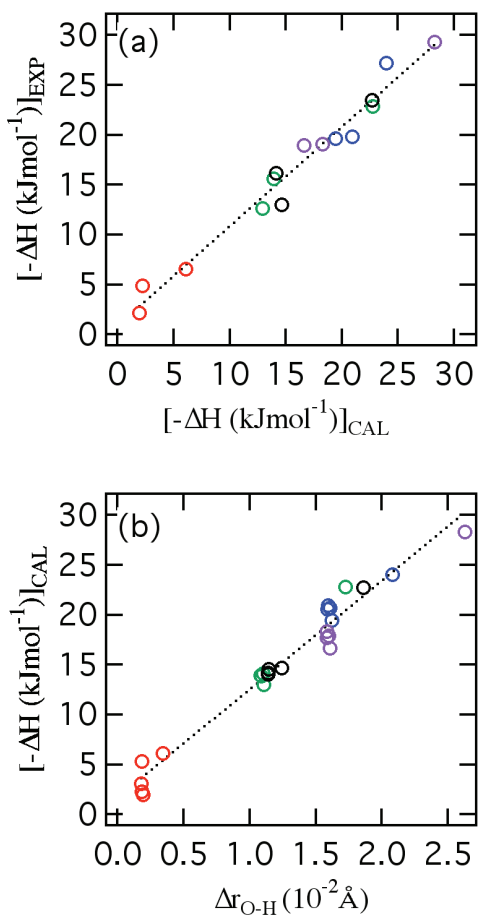

Fig. 5. (Color online) Correlation of calculated enthalpy of complex formation with (a) experimentally measured enthalpy and (b) $\mathrm{O}-\mathrm{H}$ bond variation. The color scheme is the same as in Fig. 3.

the correlation of experimentally-measured $\Delta H$ and theoretically-computed $\Delta H$ in $\mathrm{CCl}_{4}$. Experimental and computed values of $\Delta H$ are correlated $\left(R^{2}=0.97\right)$ in the linear equation, $\Delta H^{\mathrm{EXP}}\left(\mathrm{kJ} \mathrm{mol}^{-1}\right)=0.996 \Delta H^{\mathrm{CAL}}\left(\mathrm{kJ} \mathrm{mol}^{-1}\right)+0.85$, and very small deviations in the slope and the intercept are within the uncertainties in the measurement of $\Delta H$. The uncertainties of $\Delta H$ measurements have been reported from $0.3 \mathrm{~kJ} \mathrm{~mol}^{-1}$ for methanol-THF complex to as high as $2.11 \mathrm{~kJ} \mathrm{~mol}^{-1}$ for benzene-methanol complex. ${ }^{28}$

Before discussing the relation between $\Delta H$ and $\Delta \nu_{\mathrm{OH}}$ in the following section, it is imperative to see if $\Delta H$ is related to the geometric parameter, $\Delta r_{\mathrm{OH}}$, as $\Delta \nu_{\mathrm{OH}}$ does (discussed in the previous section). Figure 5(b) shows the variation of $\Delta H$ with $\Delta r_{\mathrm{OH}}$ and it is evident that $\Delta H$ is linearly correlated with $\Delta r_{\mathrm{OH}}$ in a linear equation, $-\Delta H^{\mathrm{CAL}}\left(\mathrm{kJ} \mathrm{mol}^{-1}\right)=1087 \Delta r_{\mathrm{OH}}(\AA)+1.62$, with $R^{2}=0.97$. As in the case of variation of $\Delta \nu_{\mathrm{OH}}$ and $\Delta r_{\mathrm{OH}}$, weaker base benzene, involves smaller $\Delta H$ values (an average of $\sim 3 \mathrm{~kJ} \mathrm{~mol}^{-1}$ for aliphatic alcohols and $\sim 6 \mathrm{~kJ} \mathrm{~mol}^{-1}$ for phenol). Complexes with the strong base, pyridine, have larger values of $\Delta H$ and $\Delta r_{\mathrm{OH}}$. Importantly, the linear relationship between $\Delta H$ and $\Delta r_{\mathrm{OH}}$ indicates that thermodynamic parameters are related to geometrical parameters in acid-base interactions. 

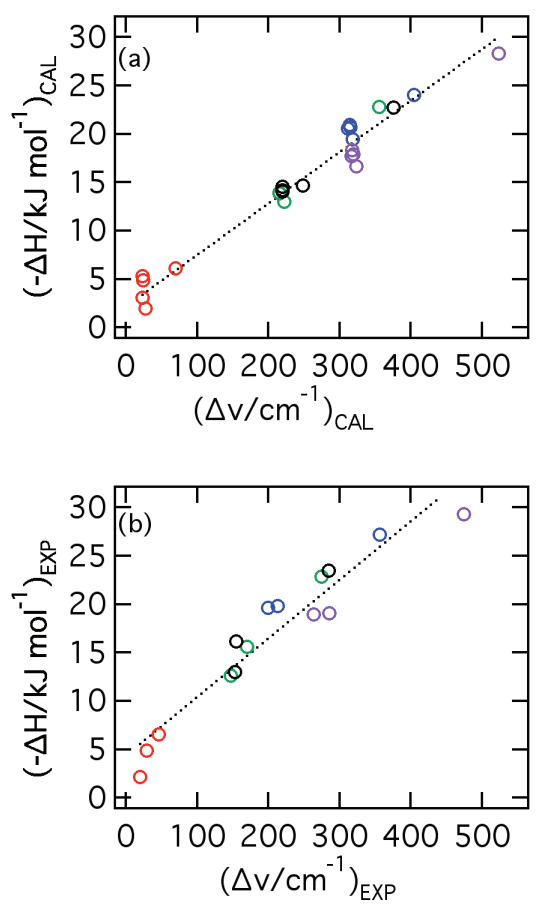

Fig. 6. (Color online) Correlation of (a) calculated and (b) experimental enthalpies with frequency shifts in $\mathrm{CCl}_{4}$. The color scheme is the same as in Fig. 3. Experimental data are from Refs. 20, 22, 28, 29, 32 and 34.

\subsection{Correlation between enthalpy and frequency shift}

Figure $6(\mathrm{a})$ represents the overall correlation of calculated $\Delta H$ and $\Delta \nu_{\mathrm{OH}}$ for 25 acid-base complexes in $\mathrm{CCl}_{4}$ (Table 2). $\Delta H$ and $\Delta \nu_{\mathrm{OH}}$ are linearly correlated with $R^{2}$ value of 0.97 as defined by Eq. (8).

$$
-\Delta H^{\mathrm{CAL}}\left(\mathrm{kJ} \mathrm{mol}^{-1}\right)=0.053 \Delta \nu_{\mathrm{OH}}^{\mathrm{CAL}}\left(\mathrm{cm}^{-1}\right)+2.15 .
$$

The linear relationship between $\Delta H$ and $\Delta \nu_{\mathrm{OH}}$ also holds for experimental reported values of 15 acid-base complexes in $\mathrm{CCl}_{4}$ with $R^{2}$ value of 0.92 .

$$
-\Delta H^{\mathrm{EXP}}\left(\mathrm{kJ} \mathrm{mol}^{-1}\right)=0.064 \Delta \nu_{\mathrm{OH}}^{\mathrm{EXP}}\left(\mathrm{cm}^{-1}\right)+3.49 .
$$

As evident from Eqs. (8) and (9), both intercept and slope of $\Delta H$ versus $\Delta \nu_{\mathrm{OH}}$ plots agree between theory and experiment. Figure 6(b) represents the correlation of available experimental values of $\Delta H$ and $\Delta \nu_{\mathrm{OH}}$ for acid-base complexes in $\mathrm{CCl}_{4}$.

The linear relationship between calculated $\Delta H$ and $\Delta \nu_{\mathrm{OH}}$ in $\mathrm{CCl}_{4}$ equally holds for complexes of each alcohol family. Table 3 summarizes $m, c$ and $R^{2}$ values obtained from fitting a linear equation to the results of $\Delta H$ versus $\Delta \nu_{\mathrm{OH}}$ (Table 2). Correlations resulting from complexes of individual alcohol as well as overall complexes are consistent. This suggests that slopes and intercepts of $\Delta H$ versus $\Delta \nu_{\mathrm{OH}}$ 
Table 3. Values of $m$ and $c$ for acid-base complexes from present calculations in $\mathrm{CCl}_{4}$.

\begin{tabular}{lccc}
\hline Acid-base complex & $m\left(\mathrm{~kJ} \mathrm{~mol}^{-1} \mathrm{~cm}\right)$ & $c(\mathrm{~kJ} \mathrm{~mol}$ & $R^{2}$ \\
\hline Methanol-base & $0.059( \pm 0.005)$ & $0.95( \pm 0.21)$ & 0.980 \\
Ethanol-base & $0.055( \pm 0.004)$ & $2.70( \pm 0.83)$ & 0.982 \\
Propanol-base & $0.059( \pm 0.002)$ & $1.77( \pm 0.33)$ & 0.998 \\
Butanol-base & $0.055( \pm 0.005)$ & $0.62( \pm 0.34)$ & 0.972 \\
Phenol-base & $0.050( \pm 0.004)$ & $3.35( \pm 1.46)$ & 0.982 \\
Overall & $0.053( \pm 0.002)$ & $2.15( \pm 0.56)$ & 0.970 \\
\hline
\end{tabular}

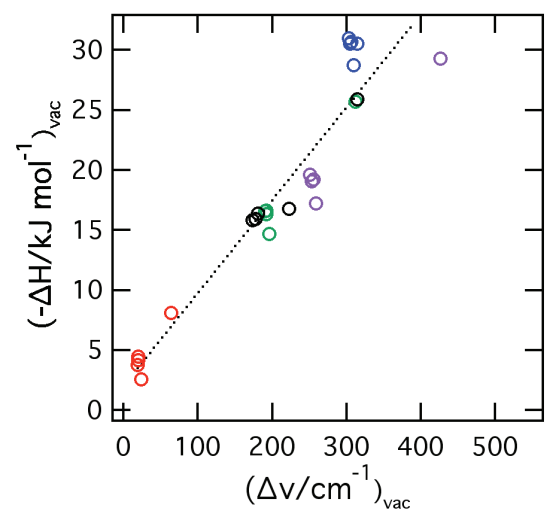

Fig. 7. Correlation of calculated enthalpies with frequency shifts in vacuum. The color scheme is the same as in Fig. 3.

plot are very slightly dependent on the type of acid. Weaker acid (aliphatic alcohol) favors slightly larger slope and slightly smaller intercept than the stronger acid (aromatic alcohol) and vice versa. These trends are supported by slightly smaller $m$ and slightly greater $c$ for phenol complexes compared to 2,2,2-trifluoroalcohol complexes. ${ }^{33}$

Importantly, the correlation between $\Delta H$ and $\Delta \nu_{\mathrm{OH}}$ is influenced by the medium in which acid-base complex is formed and hence, it is different in solution and gas phases. Figure 7 shows the correlation of $\Delta H$ and $\Delta \nu_{\mathrm{OH}}$ for 25 acid-base complexes in the gas phase. $\Delta H$ and $\Delta \nu_{\mathrm{OH}}$ are linearly correlated as defined by the equation,

$$
\left[-\Delta H^{\mathrm{CAL}}\left(\mathrm{kJ} \mathrm{mol}^{-1}\right)\right]_{\mathrm{VAC}}=0.077\left[\Delta \nu_{\mathrm{OH}}^{\mathrm{CAL}}\left(\mathrm{cm}^{-1}\right)\right]_{\mathrm{VAC}}+2.02 .
$$

The value of $c$, as is evident from Figs. 6 and 7 [Eqs. (8) and (10)], is similar in solution and gas phases. However, the value of $m$ differs by $\sim 0.024 \mathrm{~kJ} \mathrm{~mol}^{-1} \mathrm{~cm}$ between solution and gas phases. In addition, $\Delta H$ and $\Delta \nu_{\mathrm{OH}}$ are poorly correlated $\left(R^{2}=0.90\right)$ in the gas phase. As stated earlier (Fig. 3), HB distance in complexes of weak base (benzene) with alcohols are nearly equal in gas and solution phases. However, in complexes of strong bases, HB distances vary by $\sim 0.03 \AA$ (Fig. 3). Hence, $\Delta H$ and $\Delta \nu_{\mathrm{OH}}$ of strong acid-base complexes are more dependent on the 


\section{R. S. Bhatta et al.}

medium than weak acid-base complexes. Consequently, intercepts are nearly equal in solution and gas phases but slopes are different.

\section{Conclusions}

We have performed quantum chemical calculations to test the correlation between $\Delta H$ and $\Delta \nu$ among twenty-five acid-base complexes in $\mathrm{CCl}_{4}$. $\mathrm{HB}$ donors (aliphatic and aromatic) and $\mathrm{HB}$ acceptors with different atomic sites $(\mathrm{C}, \mathrm{O}, \mathrm{N})$ were considered to have $\Delta H$ and $\Delta \nu$ in a broad range; $\Delta H$ from $\sim 2 \mathrm{~kJ} \mathrm{~mol}^{-1}$ to $\sim 30 \mathrm{~kJ} \mathrm{~mol}^{-1}$ and $\Delta \nu$ from $\sim 20 \mathrm{~cm}^{-1}$ to $\sim 500 \mathrm{~cm}^{-1}$. We have found that the Badger-Bauer relationship, $-\Delta H^{\mathrm{CAL}}\left(\mathrm{kJ} \mathrm{mol}^{-1}\right)=0.053 \Delta \nu_{\mathrm{OH}}^{\mathrm{CAL}}\left(\mathrm{cm}^{-1}\right)+2.15$, holds for the complexes studied. The overall computed values of $m\left(0.0532 \mathrm{~kJ} \mathrm{~mol}^{-1}\right.$ $\mathrm{cm})$ and $c\left(2.15 \mathrm{~kJ} \mathrm{~mol}^{-1}\right)$ agree with the corresponding experimental values of $0.0578 \mathrm{~kJ} \mathrm{~mol}^{-1} \mathrm{~cm}$ and $2.64 \mathrm{~kJ} \mathrm{~mol}^{-1}$, respectively. We have also found a very small family dependence of $m$ and $c$ on complexes of a given aliphatic or aromatic alcohol. Importantly, we have also found that $\Delta H$ and $\Delta \nu_{\mathrm{OH}}$ are better correlated in solution phase than in the gas phase. Overall, reliable enthalpy of acid-base complexation can be estimated from IR frequency shift using Badger-Bauer $\Delta H$ versus $\Delta \nu$ relationship.

\section{Acknowledgments}

RB, PI and MT are grateful to The University of Akron and the National Science Foundation (Grant No. DMR0847580) for financial support of this research. AD is grateful to the National Science Foundation (Grant No. DMR-1105370) for the financial support. Part of this work used Blacklight computational resources that are provided by the Extreme Science and Engineering Discovery Environment (XSEDE), which is supported by the National Science Foundation Grant No. ACI1053575 .

\section{References}

1. G. N. Lewis, Valence and the Structure of Atoms and Molecules (The Chemical Catalog Company, Inc., New York, 1923).

2. A. Kurian, S. Prasad and A. Dhinojwala, Langmuir 26 (2010) 17804.

3. S. Prasad, H. Zhu, A. Kurian, I. Badge and A. Dhinojwala, Langmuir 29 (2013) 15727.

4. M. K. Chaudhury, Mater. Sci. Eng. R 16 (1996) 97.

5. K. L. Mittal and H. R. Anderson, Acid-Base Interactions: Relevance to Adhesion Science and Technology (VSP, Utrecht, 1991).

6. F. M. Fowkes and M. A. Mostafa, Ind. Eng. Chem. Prod. Res. Dev. 17 (1978) 3.

7. D. W. Van Krevelen, Properties of Polymers (Elsevier, Amsterdam, 1990).

8. F. M. Fowkes, D. O. Tischler, J. A. Wolfe, L. A. Lannigan, C. M. Ademu-John and M. J. Halliwell, J. Polym. Sci. Polym. Chem. Ed. 22 (1984) 547.

9. M. R. Beaver, M. J. Elrod, R. M. Garland and M. A. Tolbert, Atmos. Chem. Phys. 6 (2006) 3231. 
10. R. G. Pearson, J. Am. Chem. Soc. 85 (1963) 3533.

11. L. H. Lee, Fundamentals of Adhesion (Plenum Press, New York, 1991).

12. R. S. Drago, Struct. Bond. 15 (1973) 73.

13. R. S. Drago, G. C. Vogel and T. E. Needham, J. Am. Chem. Soc. 93 (1971) 6014.

14. V. Gutmann, The Donor-Acceptor Approach to Molecular Interactions (Plenum Press, New York, 1978).

15. C. Laurence and J. Gal, Lewis Basicity and Affinity Scales (John Wiley and Sons, 2010).

16. E. Arunan et al., Pure Appl. Chem. 83 (2011) 1619.

17. R. M. Badger and S. H. Bauer, J. Chem. Phys. 5 (1937) 839.

18. M. H. Abraham, D. V. Prior, R. A. Schulz, J. J. Morris and P. J. Taylor, J. Chem. Soc. Faraday Trans. 94 (1998) 879.

19. A. Allerhand and P. V. R. Schleyer, J. Am. Chem. Soc. 85 (1963) 371.

20. E. M. Arnett, L. Joris, E. Mitchell, T. S. R. Murty, T. M. Gorrie and P. V. R. Schleyer, J. Am. Chem. Soc. 92 (1970) 2365.

21. S. S. Barton, J. P. Kraft, T. R. Owens and L. J. Skinner, J. Chem. Soc. Perkin Trans. 2 (1972) 339.

22. I. Motoyama and C. H. Jarboe, J. Phys. Chem. 71 (1967) 2723.

23. R. S. Drago and T. D. Epley, J. Am. Chem. Soc. 91 (1969) 2883.

24. R. S. Drago, N. O'Bryan and G. C. Vogel, J. Am. Chem. Soc. 92 (1970) 3924.

25. T. D. Epley and R. S. Drago, J. Am. Chem. Soc. 89 (1967) 5770.

26. P. Goralski, J. Chem. Soc. Faraday Trans. 89 (1993) 2433.

27. M. D. Joesten and R. S. Drago, J. Am. Chem. Soc. 84 (1962) 3817.

28. M. Kone, B. Illien, C. Laurence and J. Graton, J. Phys. Chem. A 115 (2011) 13975.

29. A. S. N. Murthy and C. N. R. Rao, Appl. Spectrosc. Rev. 2 (1968) 69.

30. C. Ouvrard, M. Berthelot and C. Laurence, J. Phys. Org. Chem. 14 (2001) 804.

31. K. F. Purcell, J. A. Stikeleather and S. D. Brunk, J. Am. Chem. Soc. 91 (1969) 4019.

32. C. N. R. Rao, P. C. Dwivedi, H. Ratajczak and W. J. Orville-Thomas, J. Chem. Soc. Faraday Trans. 71 (1975) 955.

33. A. D. Sherry and K. F. Purcell, J. Am. Chem. Soc. 94 (1972) 1853.

34. J. N. Spencer, E. S. Holmboe, D. W. Firth and M. R. Kirshenbaum, J. Solution Chem. 10 (1981) 745.

35. G. C. Vogel and R. S. Drago, J. Am. Chem. Soc. 92 (1970) 5347.

36. P. R. Rablen, J. W. Lockman and W. L. Jorgensen, J. Phys. Chem. A 102 (1998) 3782.

37. M. Kone, B. Illien, J. Graton and C. Laurence, J. Phys. Chem. A 109 (2005) 11907.

38. C. Moller and M. S. Plesset, Phys. Rev. 46 (1934) 618.

39. M. J. Frisch et al., Gaussian 09, Revision C.01 (Gaussian Inc., Wallingford CT, 2010).

40. B. Mennucci and J. Tomasi, J. Chem. Phys. 106 (1997) 5151.

41. C. J. Cramer and D. G. Truhlar, Chem. Rev. 99 (1999) 2161.

42. J. Tomasi, R. Cammi, B. Mennucci, C. Cappelli and S. Corni, Phys. Chem. Chem. Phys. 4 (2002) 5697.

43. S. F. Boys and F. Bernardi, Mol. Phys. 19 (1970) 553.

44. K. E. Riley and K. M. Merz, J. Phys. Chem. B 110 (2006) 15650.

45. K. E. Riley and K. M. Merz, J. Phys. Chem. A 111 (2007) 1688.

46. A. Fujji, T. Ebata and N. Mikami, J. Phys. Chem. A 106 (2002) 8554.

47. J. Graton, F. Besseau, A. Brossard, E. Charpentier, A. Deroche and J. L. Questel, J. Phys. Chem. A 117 (2013) 13184.

48. L. D. S. Yadav, Organic Spectroscopy (Anamaya Publishers, New Delhi, 2005).

49. S. A. C. McDowell and A. D. Buckingham, J. Am. Chem. Soc. 127 (2005) 15515. 


\section{R. S. Bhatta et al.}

50. W. Wang, Y. Zhang, B. Ji and A. Tian, J. Chem. Phys. 134 (2011) 224303.

51. R. Liao, M. Zhu, X. Zhou, F. Zhang, J. Yan, W. Zhu and C. Gu, Mod. Phys. Lett. B 26 (2012) 1250088.

52. B. R. Tuttle, Mod. Phys. Lett. B 19 (2005) 683.

53. E. K. Hobbie, G. Merkle, B. J. Bauer and C. C. Han, Mod. Phys. Lett. B 10 (1996) 1219.

54. F. Zhang and D. Xue, Mod. Phys. Lett. B 23 (2009) 3951.

55. F. Zhang and D. Xue, Mod. Phys. Lett. B 23 (2009) 3943. 